\title{
Cultural factors related to the maintenance of health behaviours in Algonquin women with a history of gestational diabetes
}

\author{
S. Gaudreau, MSc (1); C. Michaud, PhD (2)
}

This article has been peer reviewed.

\begin{abstract}
Introduction: Though the cultural factors that may contribute to the diabetes epidemic in First Nations are frequently discussed, little is known about the factors that may help prevent it. In this ethnonursing study, we explore the cultural factors that help maintain health behaviours in Algonquin women who had received a diagnosis of gestational diabetes 2 to 10 years before this study.
\end{abstract}

Methods: The data were collected in two Algonquin communities through semi-structured interviews with key informants $(n=7)$ and general informants $(n=8)$ and through cultural immersion, with detailed observations being recorded into logbooks.

Results: The cultural factors that are likely to affect the prevention of diabetes are the importance of family and social ties, the possibility of preserving cultural values, the opportunity to learn behaviours through educational resources adapted to needs and culture, the chance of saving money through better diet and access to blood sugar data as a means of control.

Conclusion: In the long term, these cultural factors could influence health behaviours and thus help prevent type 2 diabetes.

Keywords: cultural factors, gestational diabetes, Algonquin women, health behaviours, health, type 2 diabetes

\section{Introduction}

Gestational diabetes (GD) is an intolerance to glucose that occurs during pregnancy ${ }^{1}$ and usually disappears after delivery. ${ }^{2}$ It is associated with complications such as macrosomia, toxemia of pregnancy and preeclampsia, which make delivery risky for both mother and baby. ${ }^{3-4}$ Further, half of those diagnosed with GD will eventually develop type 2 diabetes. ${ }^{2,5,6}$ Interventions support the adoption of health behaviours that keep blood sugar at normal levels, thus reducing the risks of complications for mother and child. ${ }^{1,4,5}$ However, interventions should take place in a cultural context and be delivered with a knowledge of their cultural significance, ${ }^{8-10}$ where culture is defined as "the learned, shared, and transmitted values, beliefs, norms, and lifeways of a particular culture that guides thinking, decisions, and actions in patterned ways"?.

A number of researchers have studied diabetes (mainly type 2) and cultural dimensions within First Nations and American Indian communities. ${ }^{10-15}$ According to these studies, First Nation peoples and American Indians perceive diabetes as a "white disease"11-13 that is inseparable from the profound socio-economic and political transformations that have characterized the relationship between Aboriginal and non-Aboriginal societies. ${ }^{12}$ In fact, the transformation of traditional ways of life has created socio-economic inequalities that have a direct impact on the health of First Nations (e.g. as a result of fewer available natural resources, less consumption of traditional foods and less access to healthy, nutritious foods in some communities). ${ }^{15}$ Further, First Nations may have different concepts of health, including a fatalistic view of diabetes. ${ }^{14}$ Food is a sign of hospitality, and slimness may be viewed negatively ${ }^{13}$ as is physical exercise such as walking. ${ }^{11,12}$ Finally, cultural differences are not reflected in treatments designed to modify lifestyles. ${ }^{13}$ All these cultural factors are impediments to health behaviours.

In this qualitative study, we undertook to understand the cultural factors that contribute to the maintenance of those health behaviours encouraged during pregnancy in Algonquin women diagnosed with GD. Such an understanding may influence the development of culturally competent care aimed at preserving those behaviours in these women as well as in their children and those around them.

\section{Methods}

The ethnographic approach is designed to deepen understanding of a cultural system from the standpoint of those who share this culture. ${ }^{16}$ The ethnonursing approach used in this study reveals an individual's lifeways and cultural vision while taking into account context. Ethnonursing aims 
to describe, understand and interpret the meaning of practices, beliefs and values of other cultures. ${ }^{8,10,17}$

\section{Population}

The two Algonquin communities (Pikogan and Lac Simon*) in this study were chosen because of their geographical proximity and because the directors of the two community health centres were interested in the study. Pikogan is in an urban setting, while Lac Simon is mainly rural. They are primarily Frenchspeaking, although the Algonquin language is also used. Pikogan is a village located about $3 \mathrm{~km}$ from the municipality of Amos. In 2008, out of 551 registered inhabitants, 278 were women. ${ }^{18}$ Approximately $52 \%$ of the population was aged less than 25 years. ${ }^{19}$ Lac Simon is located about $32 \mathrm{~km}$ from the municipality of Val-d'Or. Of the 1362 registered inhabitants in 2008, 659 were women, ${ }^{18}$ and approximately $61 \%$ of the population was aged less than 25 years. ${ }^{19}$ The two communities have similar health, educational and community services: both have a health centre, visiting doctors, an elementary school, a daycare, a police station, a church, a community room, a convenience store, a community radio station, a youth centre and buildings belonging to each Band Council. Lac Simon also has a high school, a post office and a restaurant, while Pikogan has a sports arena.

\section{Informant selection and recruitment}

An ethnonursing study involves two kinds of participants: key informants and general informants. ${ }^{8,9}$ The key informants in this study ( $\mathrm{n}=7$ ) were directly concerned with the issue: they had been diagnosed with GD and had received care in their community health centre (Table 1). Inclusion criteria were the following: Algonquin; aged 18 years plus; diagnosed with GD 2 to 10 years before the start of this study; received health care in the Algonquin community when given the diagnosis of GD; neither breastfeeding nor pregnant during the study. The key informants were recruited by three of the general informants.

For reasons of anonymity, age and education are not given, though mean age was 34 years (range: $29-40$ years) and half had not completed high school. We assigned each key informant a fictitious given name similar to those used in the two communities in the order of the interviews. Thus, the first person interviewed at Lac Simon was assigned the letter $\mathrm{A}$ and given a name starting with $a$ (e.g. Amy), and so on until $d$. To differentiate from them, the women of Pikogan were given fictitious names that began with $i$ and continued until $k$ (see Table 1).

General informants have a more general view of the issue. They were introduced to us by the resource people who, in turn, were our first point of contact in the communities. General informants were willing to speak freely of their experience with the community and to give feedback on the participant observation notes. A total of 8 people were consulted as general informants: 4 nurses, a nutritionist, a social worker, a nursing assistant and a dental hygienist; 2 were First Nations and 6 worked in Lac Simon. They had between several months and eight years of experience in the community ( $\bar{x}=3.5$ years).

\section{Data collection}

The data were collected through participantobservers and semi-structured interviews. Our cultural immersion in the Pikogan and Lac Simon communities took place over 2 months in March and April 2006, during which time we observed the activities of health workers; participated in collective kitchen activities, community meals, home visits, etc.; and made observations on the environment, for example, the food in the convenience store and the school canteen ("Club des petits déjeuners"). We used a logbook to record our observations in a condensed, consistent format to encourage reflection, as recommended by the Observation-Participation-Reflection Enabler. ${ }^{8}$ We interviewed key informants in French, usually at the community health centre, using semi-structured interviews based on Leininger's cultural factors ${ }^{8,9}$ and the Taylor et al. study. ${ }^{14}$ (see Appendix A). The interviews, which lasted on average

TABLE 1

Summary of the sociodemographic and health profiles of the key informants $(n=7)$

\begin{tabular}{|c|c|c|c|c|c|c|c|c|}
\hline \multirow{2}{*}{$\begin{array}{l}\text { Fictitious } \\
\text { name }^{\mathrm{a}}\end{array}$} & \multirow[t]{2}{*}{ Community } & \multicolumn{3}{|c|}{ Language spoken } & \multirow{2}{*}{$\begin{array}{l}\text { Time of GD } \\
\text { diagnosis }\end{array}$} & \multirow{2}{*}{$\begin{array}{l}\text { Diagnosed } \\
\text { with T2D }\end{array}$} & \multirow[t]{2}{*}{ BMI, kg/m² } & \multirow{2}{*}{$\begin{array}{c}\text { Number of } \\
\text { children }\end{array}$} \\
\hline & & Algonquin & French & English & & & & \\
\hline Amy & Lac Simon & Yes & Yes & No & 1999 & Yes & 36.0 & 6 \\
\hline Brenda & Lac Simon & No & Yes & No & 2003 & Yes & 28.3 & 6 \\
\hline Céline & Lac Simon & No & Yes & No & 2004 & No & 36.0 & 5 \\
\hline Diane & Lac Simon & Yes & Yes & No & 2003 & No & 34.4 & 4 \\
\hline Isabelle & Pikogan & No & Yes & Yes & 2003 & No & 33.9 & 4 \\
\hline Julie & Pikogan & No & Yes & Yes & 2003 & No & 36.6 & 5 \\
\hline Kimberly & Pikogan & No & Yes & No & 2003 & No & 28.9 & 5 \\
\hline
\end{tabular}

Abbreviations: BMI, body mass index; GD, gestational diabetes; T2D, Type 2 diabetes.

${ }^{\text {a }}$ A fictitious given name (similar to those found in the two communities) was assigned to the key informants according to the order of the interviews. Thus, the first person interviewed at Lac Simon was assigned the letter A and a given name starting with the letter $a$ and so on until D. To differentiate the women of Pikogan, the fictitious names began with the letter I and continued until the letter $\mathrm{K}$.

* The directors of both community health centres agreed to the communities being named in this article. 
for 47 minutes, were recorded to allow subsequent verbatim transcription and analysis.

The focus of the interviews was on maintaining health behaviours and not on obstacles to maintaining them. This study was not intended to influence or judge existing health behaviours.

\section{Data analysis}

We analyzed our observations in four phases ${ }^{10}$ and followed Miles and Huberman's process of data analysis. ${ }^{20}$ The first phase was based on our observations during the cultural immersion and the interviews with the Algonquin women. The log book entries helped to place the verbatim interviews in context. In the second phase, we conducted a vertical analysis of the verbatim interviews, classifying each sentence according to Leininger's cultural factors, ${ }^{8,9}$ in order to reveal the cultural factors within each transcript. The third phase, the horizontal analysis of patterns and context of the cultural factors, resulted in a collection of those cultural factors that contributed to the maintenance of the health behaviours encouraged during the pregnancies of all the interviewees. During the fourth phase, we confirmed the themes and subthemes with the key and general informants. Only one theme was reconstructed after this confirmation: it concerned the importance of friends in the maintenance of health behaviours.

Appendix B lists the strategies used to ensure rigorous data analysis.

\section{Ethical considerations}

The ethics board of the clinical research centre of the Centre hospitalier universitaire de Sherbrooke and the directors of the Pikogan and Lac Simon health centres approved this study. It followed the guidelines set by the Tri-Council Policy Statement ${ }^{21}$ for research projects conducted on lands under the jurisdiction of a First Nations authority, including obtaining written approval from the responsible community bodies and masking the identities of participants.

\section{Results and discussion}

Table 2 summarizes the main cultural factors that contributed to the maintenance of health behaviours, arranged according to five themes and several subthemes. The results are presented and discussed in the same section.

\section{Family and social ties as motivation and support for maintaining health behaviours}

Family and social ties were the primary motivation for maintaining health behaviours. As found by Taylor et al., ${ }^{14}$ the Algonquin women participating in this study did not want their children to develop diabetes: "Yes, I kept eating the same way. I did it mainly for myself and my daughter. I don't want her to have adolescent diabetes either. She's overweight, and I don't want that for her. So I kept my way of eating... but more for myself... and her too" (Julie ${ }^{\dagger}$, line 528).

The experiences of key informants' parents was a constant reminder of the possible complications: "I can’t allow myself to have complications like that in just five years... My father was on dialysis, and my grandmother had to have an amputation” (Amy, line 45).

The encouragement of family and the community was important: "Everyone tells me they can see I am losing weight. It helps when someone tells you that" (Julie, line 840). Also important was offering support: “... We tried to come up with a kind of diet that we could go on, her and me, to help our diabetes” (Julie, line 359). Another way of encouraging was by giving advice: "[My sister] told me: 'That has too much sugar in it... That's what's in there. How many calories are in a meal if you go to a restaurant?' Because my sister is diabetic. That really helped me too" (Kimberly, line 378).

The communities supported some physical activities, mainly walking, by painting these in a positive light: "I think people

TABLE 2

Factors promoting the maintenance of health behaviours in the key informants $(n=7)$

\begin{tabular}{|c|c|c|}
\hline Factors & Theme & Subthemes \\
\hline Family and social & $\begin{array}{l}\text { Family and social factors as motivation and support } \\
\text { for the maintenance of health behaviours }\end{array}$ & $\begin{array}{l}\text { Concern for children's health } \\
\text { Family and community support } \\
\text { Family members' experiences } \\
\text { Desire to be together }\end{array}$ \\
\hline $\begin{array}{l}\text { Lifestyle and } \\
\text { cultural }\end{array}$ & $\begin{array}{l}\text { Adopting new health behaviours while preserving } \\
\text { cultural values }\end{array}$ & $\begin{array}{l}\text { Adaptation of traditional foods } \\
\text { Diet modification } \\
\text { Walking } \\
\text { Synergy between diet and walking }\end{array}$ \\
\hline Educational & $\begin{array}{l}\text { Learning through educational resources adapted to } \\
\text { needs and culture }\end{array}$ & $\begin{array}{l}\text { Capacity for self-learning } \\
\text { Cultural adaptation of teaching and support }\end{array}$ \\
\hline Economic & Saving money through better diet & \\
\hline Technological & $\begin{array}{l}\text { Access to blood sugar data through technological } \\
\text { advances with glucometers }\end{array}$ & $\begin{array}{l}\text { Glucometers as a means of immediately checking whether blood sugar is normal } \\
\text { Downloading eliminates the need to write the information down }\end{array}$ \\
\hline
\end{tabular}

† When doing so did not affect the phenomena under study, we deleted or changed certain facts to preserve the anonymity of the key informants. 
are starting to see the value of it ..." (Kimberly, line 939). Walking lets people socialize as they engage in a physical activity: "I go walking with a friend. We talk and chat while we walk... sometimes I go with my boyfriend” (Kimberly, line 947).

Family or social support was very important to the participants, and lack of it makes it more difficult for some First Nations women with diabetes to effectively adopt new health behaviours. ${ }^{12}$ From a psychosocial standpoint, individuals who receive peer support run less of a risk of developing physical or mental problems. ${ }^{22}$

\section{Adopting new health behaviours while preserving cultural values}

The second theme consists of adopting new health behaviours, especially those related to diet and physical activity, while preserving cultural values.

According to the Algonquin women, their traditional diet can be adapted to help maintain health behaviours. The methods of cooking certain traditional foods and using less fat in food preparation can contribute to good health and prevent diabetes. The key informants said they could choose game meats that have less fat than others (e.g. moose versus beaver).

The key informants changed their diets following a GD diagnosis and followed a balanced diet that reflected the goals of Canada's Food Guide. ${ }^{23}$ The changes consisted of additions to traditional foods, not their removal. Due to their symbolic aspect, the use of traditional foods and methods of preparation are important to First Nations peoples, and they feel accepted and respected when health care professionals take these traditional practices into account. ${ }^{24}$

The key informants said that they would like a cookbook that included traditional foods to help them manage their diabetes; this would also uphold respect for traditional values. Both health centres held community meals that included traditional foods adapted for a special diet, for example, banik (traditional bread) prepared with whole-wheat flour, and also distributed the recipes.
The participants also considered exercise key to maintaining a healthy weight and preventing type 2 diabetes: "Exercise is the important thing for me because when you train a lot, diet follows. I know that when I was walking a lot, I was less likely to eat chips and drink soft drinks" (Kimberly, line 881). Walking was the physical activity that was mentioned most often during the interviews because of its numerous advantages, not least that it both energizes and relaxes: "Walking? Yes, it helps me a lot with stress because I work and I have five children at home under the age of 10" (Julie, line 746). Walking can also be compatible with family values (e.g. walking with the children) and the participants' lifestyles (e.g. not having a car, working outside the home).

The significance of weight loss as described by the participants is supported by research that shows that overweight and lack of physical activity are risk factors for type 2 diabetes, ${ }^{2}$ and that a $5 \%$ to $10 \%$ weight loss through changes in diet and physical activity can prevent or delay the emergence of type 2 diabetes in certain persons with glucose intolerance. ${ }^{25}$ Critical to this was the participants' perception of thinness and overweight. Although each had a high body mass index (BMI $\bar{x}=33.4$ ), they did not associate slenderness with disease, unlike people in other studies. ${ }^{13}$ Rather, they had a negative perception of overweight, as did the women of the Oklahoma First Nations. ${ }^{14}$

\section{Learning new behaviours through educational resources adapted to needs and culture}

According to the key informants, certain ways of acquiring new knowledge provide more choices and freedom: the third theme addresses the opportunity of learning with educational resources adapted to needs and culture. For example, self-learning through reading helps prevent frequent visits to the health centre and provides a certain form of autonomy where there is an overall lack of other resources: “... usually it meant I didn't have to go anywhere... because... since there are no training sessions on that here, and often there was a long wait to see the nurse" (Céline, line 1168). The capacity for self-learning and keeping informed increases the chances of staying healthy: "Are there things you do to be able to say 'that's important for me for staying healthy'?” (Sylvie, line 1183, interviewing Isabelle). "Yes, keeping informed, that's all!” (Isabelle, line 1187). Daniel and Messer $^{26}$ also found that First Nations place considerable value on autonomy and may even be wary of health education initiatives they perceive as an occidental intrusion into their way of life. This preference for autonomy is supported by the shared decision-making framework, ${ }^{27}$ which could be more acceptable to them than regular diabetes classes.

The Algonquin women who participated in this study mentioned the importance of learning with educational resources and supports adapted to their needs and culture, especially to their way of life. For example, they wanted to learn how to choose ingredients to preserve or improve nutritional values in their traditional foods. "I made banik at home using vegetable oil. I wanted to change oils, but I didn't know which one to choose...the one with the lowest fat (the least unhealthy one)" (Julie, line 618). They also wanted to learn ways that uphold the traditional Algonquin way of life, which involves frequently being in the woods: "What we eat, the Anicinabek [Algonquins]... [laughter]... we often go out in the woods as well... They should think about that...we go out in the woods" (Brenda, line 855).

This cultural adaptation of learning can also take place through other adapted activities. Several key informants mentioned the idea of a forest "diabetes camp" co-facilitated by the nurse and the nutritionist who would incorporate instruction into traditional activities (e.g. walking in the woods, snowshoeing). Macaulay et $\mathrm{al}^{.28}$ also understood the importance of adapting instruction to Mohawk culture to positively affect diabetes prevention.

According to the key informants, the continual illness prevention and health promotion activities of health care professionals were key to maintaining health behaviours. The health care professionals would frequently encourage those making progress with respect to their health, especially people living with 
diabetes of any type. They took advantage of community events to hold their health promotion activities. They adapted appointments to the Algonquin way of life: instead of making appointments for a fixed time and date, they intervened immediately, adapting to a culture-specific concept of time described by the general informants as "now or never."

Some general informants maintained that, compared to previous generations, the younger generation of Algonquin women are more likely to make individual life choices. Further, if they feel good in their everyday lives, they tend to "shop well" and buy healthy, nutritionally balanced foods. Some key informants said they felt more comfortable with the First Nations nurse who questioned them regularly about drug and alcohol use, the support given by their family, etc. This holistic approach was in line with the values of the women in both communities.

Even though previous studies found that educational activities are not always adapted to First Nations culture, according to the key informants the health care professionals facilitated the adoption of health behaviours and organized a number of activities that were culturally adapted to Algonquin women, as recommended by Daniel and Messer. $^{26}$

\section{Saving money through better diet}

After learning how to manage their diabetes, a number of participants found themselves saving money by eating a better diet. Some said they went to restaurants less often or ate differently when they did go out to eat: "I didn't eat out as often. It became less expensive to eat out because I cut down on my portions" (Isabelle, line 1062). They maintained the health behaviours after pregnancy because of the money-saving aspect of the better diet.

During their pregnancy, some of the participants took part in community kitchens funded by the Canada Prenatal Nutrition Program. ${ }^{29}$ They learned about the costs of different foods as well as how to read flyers and make shopping lists: "I often looked at the flyers... I went to the places where there were better specials"
(Céline, line 1110). They said that as a result they could make more informed choices about the quality and quantity of foods, and that this affected their budget.

\section{Access to information on blood sugar using glucometers}

The final theme concerns access to blood sugar monitoring through technology. Several participants in both communities used a glucometer to measure their blood sugar levels: "It shows whether...your blood is normal and all that!... You see right away whether your blood is normal" (Céline, line 182). Some of the participants who did not currently have diabetes continued to use their glucometers regularly to monitor their blood sugar as a preventive means.

Technology available to the Algonquin women in both community health centres allows them to monitor and compare their blood sugar levels more easily by downloading the glucometer data in a graphic so that they do not have to record their blood sugar levels. Self-monitoring can reduce the use of clinical and professional care, and users feel more self-confident and independent, both important elements in self-management. ${ }^{30}$

\section{Limitations of the study}

This study sheds light on cultural factors that contribute to the maintenance of health behaviours in a First Nation population. This perspective is primarily that of the Algonquin women who received educational services and support for GD during their pregnancy and post-partum. General informants of both Algonquin and nonAlgonquin origin supported the themes that emerged from the data. As a result of basing this study in the two communities of Lac Simon and Pikogan, we have taken into account about one-quarter of the Algonquin population in Quebec, ${ }^{31}$ though not necessarily those living in urban communities.

\section{Conclusions}

While this study is exploratory in nature, it suggests that cultural practices can influence the maintenance of health behaviours among Algonquin women who have had GD.

Our study found that an approach centred on friends and family rather than on the individual could help Algonquin women who have had GD maintain healthy behaviours. Cultural adaptations of health education were a priority in the maintenance of health behaviours for the study participants. Health care professionals could continue to develop activities for Algonquin women that are culturally adapted, such as those in the woods or in environments conducive to physical activity. Working closely with their clients, health care professionals can help them make full use of their own abilities to become autonomous and improve their well-being. ${ }^{32}$ In addition, Health Canada has published a new Canada's Food Guide, including one specifically for First Nations, Inuit and Métis. ${ }^{23}$ The adapted version could be used to explain the nutritional, social and spiritual value of traditional foods and to explain the harmful effects of processed foods as part of a strategy to reduce obesity and obesityrelated chronic disease such as diabetes. ${ }^{33}$ The Algonquin women in the study also found that they were able to save money through a more nutritious diet.

Our study found that using a glucometer to measure blood sugar levels seemed to empower participants, indicating that it could be used as a tool in preventive self-management practices. This is at variance with the 2009 recommendations on glucometer use made by the Canadian Agency for Drugs and Technologies in Health (CADTH). ${ }^{34}$ In its review the CADTH did not notice significant clinical improvement of the A1C concentrations in non-insulin-dependent patients. ${ }^{34}$

The themes emerging from this study present a unique cultural perspective that could help health care professionals and First Nation communities develop services and strategies specifically for Algonquin women who have had a GD diagnosis. These services and strategies could contribute to the health and well-being of pregnant women and their children and in the prevention of type 2 diabetes in the Algonquin population. 


\section{Acknowledgements}

The authors wish to thank those who helped recruit participants for this study: Suzanne Paré, Nurse (Pikogan Health Centre); Karen Morency, Nutritionist (Lac Simon Health Centre); and Rose Dumont, Nurse (Lac Simon Health Centre). We also acknowledge the collective contribution of the communities to this research as well as that of the individual contributions described in this study.

We thank the following for their financial contribution in the form of scholarships: Health Canada, Tembec, National Aboriginal Achievement Foundation, and the Ordre régional des infirmières et infirmiers de la
Montérégie. We thank Health Canada as one of our authors was an employee at the time this paper was being written. Finally, we thank the Abitibiwinni Band Council for a school allowance to help young Algonquins continue their education.

\section{Appendices}

\section{APPENDIX A}

Interview guide (based on Taylor et al. ${ }^{14}$, p.9)

\section{World view}

- Describe your current health.

- Describe how you feel about your health.

-What do you do to stay healthy?

- Do you have any health concerns?

- What are the major health concerns of Aboriginal women?

- What comes to mind when I say "gestational diabetes"?

- What do you think happens to a woman once she develops gestational diabetes?

- And after her pregnancy?

- What do you think happens to the baby of a woman who develops gestational diabetes?

- And after his or her birth?

-What does a woman in your community do if she is diagnosed with gestational diabetes?

- In your community, how do people explain gestational diabetes?

- Do you think that gestational diabetes is more or less frequent in your community?

- How does your community care for a woman who is diagnosed with gestational diabetes?

Language

- What are the words used to speak about diabetes?

- What are the words health care professionals use to speak about diabetes?

Technological factors

- How did you monitor the sugar in your blood when you were pregnant?

- Are there technological tools that help manage gestational diabetes?

Religious and philosophical factors

- Did you consult with a wise man or a shaman when you had gestational diabetes? Explain.

-What treatments do you trust to treat gestational diabetes?

\section{Social and family factors}

-What is the role of members of your family regarding gestational diabetes?

- How would you make decisions regarding gestational diabetes in your family? In your community?

Cultural values and way of life

- What do you think causes gestational diabetes?

- Why do you think these things (mentioned above) cause gestational diabetes?

- How did you react when you received the diagnosis of gestational diabetes?

- Which changes did you make during your pregnancy after you learned of the diagnosis of gestational diabetes?

- Which changes didn't you make among those that were recommended?

-What did you maintain in the changes you made while pregnant?

- What is your main concern about having gestational diabetes?

- In your view what is good nutrition or a balanced diet?

- In your community what do you consider to be traditional foods? Are they part of the regular diet of your community?

- Do you think eating a more traditional diet would help prevent diabetes or gestational diabetes?

- Which foods should a woman with gestational diabetes eat?

- In your community can a woman with gestational diabetes exercise? 
APPENDIX A (continued)

\section{Interview guide (based on Taylor et al. ${ }^{14}, \mathrm{p.9}$ )}

Political and legal factors

- How does the community show its concern for women who have gestational diabetes?

- What do you think the Band Council or the government could do to help women that have gestational diabetes?

Economic factors

- What are the main expenses caused by having gestational diabetes?

- Did those expenses have a repercussion on your budget?

Educational factors

- How did you learn what you know about gestational diabetes?

- Where do you find your information about diabetes?

- To what extent are you satisfied with the information you received on gestational diabetes? How was this information adapted to your culture?

Care practices

- What are the most important behaviours to maintain your health?

- How did you come to associate health with these behaviours?

- In your opinion, are those behaviours also important for your children?

- What are the health behaviours that you would like to pass on to your children?

- How do you try to pass on those health behaviours to your children?

- Do you think these behaviours have an impact on diabetes or gestational diabetes?

- If yes, what kind of impact?

- If not, which health behaviours could have an impact?

- What could a woman who has/had gestational diabetes do to try to prevent or to delay onset of diabetes?

APPENDIX B

Strategies used to ensure rigour in analysis of data

\begin{tabular}{|c|c|c|}
\hline Criteria & Definition $^{17}$ & Strategies \\
\hline \multirow[t]{3}{*}{ Credibility } & \multirow[t]{3}{*}{ Accuracy, truthfulness and authenticity of results } & Verbatim transcript \\
\hline & & Sentence by sentence analysis \\
\hline & & Inter-rater agreement \\
\hline Confirmability & Approval of results by informants & Results submitted to informants and modification of a theme \\
\hline Meaning in context & $\begin{array}{l}\text { Meaning given to results reveals one of people from } \\
\text { a specific context }\end{array}$ & Rich and dense description of the context, supported by notes in the logbook \\
\hline \multirow[t]{2}{*}{ Recurrent patterning } & \multirow{2}{*}{$\begin{array}{l}\text { Detailed examination of data to discover the repetitions } \\
\text { of themes, patterns, behaviour reflecting a trend }\end{array}$} & Horizontal analysis \\
\hline & & Inter-rater agreement \\
\hline Saturation & $\begin{array}{l}\text { Results answer the goal of the research and additional data } \\
\text { won't help in the understanding of the phenomenon }\end{array}$ & Confirmation by informants that the phenomenon was adequately covered \\
\hline \multirow[t]{4}{*}{ Transferability } & \multirow{4}{*}{$\begin{array}{l}\text { Application of results to other contexts, situations } \\
\text { or cultures }\end{array}$} & Conference given to the Rapid Lake \\
\hline & & Presentation to First Nations and Inuit Health, Quebec Region \\
\hline & & Rich and dense description of the context \\
\hline & & Publication of an article in a scientific journal \\
\hline
\end{tabular}




\section{References}

1. Canadian Diabetes Association Clinical Practice Guidelines Expert Committee. Canadian Diabetes Association 2008 clinical practice guidelines for the prevention and management of diabetes in Canada. Can J Diabetes. 2008;32(suppl 1):S1-S201.

2. Diabetes in Canada [Internet]. 2nd ed. Ottawa (ON): Health Canada; 2002 [cited 2010 Nov 2]. Available at: http:// www.phac-aspc.gc.ca/publicat/dic-dac2 /english/01 cover-eng.php

3. Lowdermilk DL, Perry S, Bobak IM. Soins infirmiers: périnatalité. Laval : Groupe Beauchemin Éditeur Inc.; 2003.

4. Masseboeuf N, Corset E. Diabète gestationnel, nécessité d'une éducation diététique. Soins. 2002;667:17-9.

5. Boivin S, Derdour-Gury H, Perpetue J, Jeandidier $N$, Pinget $M$. Diabète et grossesse. Ann Endocrinol (Paris). 2002;63(5):480-7.

6. Rodrigues S, Robinson E, Gray-Donald K. Prevalence of gestational diabetes mellitus among James Bay Cree women in Northern Quebec. CMAJ. 1999;160(9):1293-7.

7. Setji TL, Brown AJ, Feinglos MN. Gestational diabetes mellitus. Clinical Diabetes. 2005;23(1):17-24.

8. Leininger M, McFarland MR. Transcultural nursing: concept, theories, research and practice. 3rd ed. Toronto (ON): McGraw-Hill Medical Publishing Division; 2002.

9. Leininger M, McFarland MR. Culture care diversity and universality: a worldwide theory of nursing. 2nd ed. Boston (MA): Jones and Bartlett; 2006.

10. McFarland MR. The ethnonursing research method and the culture care theory: implication for clinical nursing practice. In: Parker $M$, editor. Nursing theories and nursing practice. Philadelphia (PA): F.A. Davis Company; 2001. p. 377-90.

11. Roy B. Le diabète chez les autochtones: regard sur la situation à Betsiamites, Natashquan et La Romaine. Recherches amérindiennes au Québec. 1999;XXIX(3):3-18.
12. Roy B. Sang sucré, pouvoirs codés et médecine amère. Diabète et processus de construction identitaire: Les dimensions socio-politiques du diabète chez les Innus de Pessamit [PhD thesis], [Sainte-Foy (QC)]: Université Laval; 2002.

13. Smith-Morris CM. Reducing diabetes in Indian Country: lessons from the three domains influencing Pima diabetes. Hum Org [Internet]. 2004;63(1):34-46.

14. Taylor C, Keim KS, Sparrer A, Van Delinder J, Parker S. Social and cultural barriers to diabetes prevention in Oklahoma American Indian women. Prev Chronic Dis. 2004;1(2);1-10.

15. Travers KD. Using qualitative research to understand the sociocultural origins of diabetes among Cape Breton Mi'kmaq. Chronic Dis Can. 1995;16(4).

16. Fortin M-F. Le processus de la recherche: de la conception à la réalisation. VilleMont-Royal (QC): Décarie Éditeur Inc; 1996.

17. Leininger MM. Theory of culture care diversity and university. In: Parker M, editor. Nursing theories and nursing practice. Philadelphia (PA): F.A. Davis Company; 2001. p. 361-76.

18. Welcome to First Nation Profiles [Internet]. Gatineau (QC): Aboriginal Affairs and Northern Development Canada; 2008 [updated 2008 Nov 14; cited 2008 Nov 19]. Available at: http://pse5-esd5.ainc-inac.gc.ca/fnp/

19. 2006 Community Profiles [Internet]. Ottawa (ON): Statistics Canada; 2009 [cited 2008 Apr 20]. Available at: http:// www12.statcan.ca/census-recensement /2006/dp-pd/prof/92-591/index.cfm?Lang = E

20. Miles MB, Huberman, MA. Analyse des données qualitatives. Paris (FR): De Boeck Université; 2003.

21. Canadian Institutes of Health Research; Natural Sciences and Engineering Research Council of Canada; Social Sciences and Humanities Research Council of Canada. Tri-Council Policy Statement: ethical conduct for research involving humans [Internet]. Ottawa (ON): Government of Canada; 2010 [cited 2010 Mar 2]. Available at: http:// www.pre.ethics.gc.ca/pdf/eng/tcps2 /TCPS_2_FINAL_Web.pdf
22. Devault A, Fréchette L. Le soutien social: ses composantes, ses effets et son insertion dans les pratiques sociosanitaires. In: Carroll G, editor. Pratiques en santé communautaire. Montréal (QC): Chenelière Éducation; 2006.p. 141-52.

23. Health Canada. Eating well with Canada's food guide - First Nations, Inuit and Métis. Ottawa: Government of Canada, 2007 [cited 2008 Nov 24]. Available at: http:// www.hc-sc.gc.ca/fn-an/food-guide-aliment /fnim-pnim/index-eng.php

24. Tom-Orme L. Transcultural nursing and health care among Native American peoples. In: Leininger $M$, McFarland MR, editors. Transcultural nursing: concept, theories, research and practice. 3rd ed. Toronto (ON): McGraw-Hill Medical Publishing Division; 2002. p. 429-40.

25. American Diabetes Association. Diagnosis and classification of diabetes mellitus. Diabetes Care. 2008;31(suppl. 1):S55-S60. doi:10.2337/dc08-S055.

26. Daniel M, Messer LC. Perceptions of disease severity and barriers to self-care predict glycemic control in Aboriginal persons with type 2 diabetes mellitus. Chronic Dis Can. 2002;23(4):130-8.

27. Quill T E, Brody H. Physician recommendations and patient autonomy: finding a balance between physician power and patient choice. Ann Intern Med. 1996;125(9):763-9.

28. Macaulay A C, Cargo M, Bisset S, Delormier T, Lévesque L, Potvin L, et al. Community empowerment for the primary prevention of type 2 diabetes: Kanien'keha:ka (Mohawk) ways for the Kahnawake Schools Diabetes Prevention Project. In: Ferreira MK, Lang GC, editors. Indigenous peoples and diabetes: community empowerment and wellness. Durham (NC): Carolina Academic Press; 2006. p. 407-33.

29. Public Health Agency of Canada. The Canada Prenatal Nutrition Program: A decade of promoting the health of mothers, babies and communities. Ottawa (ON): Government of Canada; 2007 [cited 2008 Dec 29] [Catalogue No.: HP10-11/2007]. Available at: http://www.phac-aspc.gc.ca/hp-ps/dca-dea /publications/pdf/mb_e.pdf 
30. Health Promotion and Programs Branch, Health Canada. Supporting self-care: the contribution of nurses and physicians - an exploratory study. Ottawa (ON): Health Canada; 1997.

31. Secrétariat aux affaires autochtones. Aboriginal population in Québec [Internet]. Québec: Government of Québec; [cited 2005 Sep 26]. Available at: http:// www.autochtones.gouv.qc.ca/nations /population_en.htm

32. Hagan L, Proulx S. L'éducation pour la santé: le temps d'agir. Linfirm Que. 1996:3(3);44-52.

33. Federal, provincial and territorial governments of Canada; National Aboriginal Organizations. Blueprint on Aboriginal Health: A 10-Year Transformative Plan. November 24-25, 2005 [Internet]. [Cited 2008 Nov 24]. Available at: http://www.hc-sc.gc.ca/hcs-sss/alt_formats /hpb-dgps/pdf/pubs/2005-blueprint -plan-abor-auto/plan-eng.pdf

34. COMPUS. Summary report: optimal prescribing and use of blood glucose test strips for self-monitoring of blood glucose [Internet]. Ottawa (ON): Canadian Agency for Drugs and Technologies in Health; 2009 [cited 2011 Oct 8]. Available at: http:// www.cadth.ca/media/pdf/C1109_bgts _summary_report_e.pdf 